\title{
Super-Homem em busca da felicidade Aristotélica*
}

\author{
Gelson Vanderlei Weschenfelder ${ }^{l}$ \\ Universidade Federal do Rio Grande do Sul
}

\begin{abstract}
Um dos mais notáveis fenômenos da cultura popular da atualidade é o ressurgimento vigoroso das histórias em quadrinhos de Super - Heróis que, no entanto, não são tão inocentes como parecem. Elas não trazem só o divertimento ao leitor. Elas introduzem e abordam de forma vivida as questões se suma importância enfrentadas pelos seres humanos, referentes à ética, à responsabilidade pessoal $\mathrm{e}$ social. Super-Homem um dos super-heróis mais conhecido no mundo dos quadrinhos e, um dos primeiros a surgir, traz estas questões em suas histórias. A atitude deste super-herói aborda de forma vivenciada, questões éticas referendadas pelo filosofo grego Aristóteles.
\end{abstract}

Palavras chave: Super-Homem-Histórias em Quadrinhos - Ética - Aristóteles
One of the most remarkable phenomena of popular culture today is the resurgence of powerful stories Superheroes comics, which however are not as innocent as they seem. They not only bring fun for the reader. They introduce and discuss the vividly the issues faced are very important by humans, relating to ethics personal and social responsibility. Superman one of the most popular superheroes in the world comics, and one of the first to emerge, brings these issues in the stories. The attitude of this superhero addresses so experienced, ethical issues countersigned the Greek philosopher Aristotle.

Keywords: Superman - Comics Books Ethics and Aristotle

\section{Introdução}

Tos confins do Universo havia um planeta condenado à extinção. Pouco 1 antes de sua destruição, o último filho de Kripton, um bebê chamado Kal$\mathrm{El}^{2}$, foi mandado por seu pai para o planeta Terra, a fim de salvá-lo (SIEGEL \& SHUSTER, 2007; p. 6). Enquanto seu planeta explodia, o último kriptoniano a perecer deve ter calculado, com extraordinária sutileza, a rota de seu projétil (THOMAS \& LARK, 2001; p. 4), que veio a cair no planeta Terra,

\footnotetext{
* Superman in the pursuit of Aristotlean happiness

${ }^{1}$ Graduado em Filosofia pela Universidade do Vale do Rio dos Sinos- Unisinos e Mestre em Educação pelo Centro Universitário La Salle - Unilasalle. Aluno especial educação FACED-UFRGS. Docente da Faculdade Cesuca. Endereço para correspondências: Rua Augusto Jaeger Filho, 224, Bairro São João, Montenegro, RS, 95780-000 (gellfilo@terra.com.br).

${ }^{2}$ Que significaria "Filho das Estrelas" no idioma kryptoniano. E no hebraico "vaso de Deus".
} 


\section{UMANAS}

na cidade norte-americana chamada Smallville, no estado de Kansas, onde foi encontrado por um simpático casal de fazendeiros e sem filhos: Jonathan e Martha Kent. Foi batizado de Clark, e foi criado como filho legítimo. Já em sua infância mostrava-se diferente dos humanos, e enquanto crescia foi descobrindo que podia desafiar a gravidade, que tinha uma força descomunal e era mais rápido que qualquer coisa criada na Terra. Com muito amor e carinho, seus pais adotivos, o ensinaram a compreender e usar seus dons. Este amor e carinho foram de fundamental importância na vida do rapaz (THOMAS \& LARK, 2001; p. 5). Ele jurou proteger o mundo que o adotou, usando seus dons em prol da justiça e da paz, tornando-se, assim, o Super - Homem ${ }^{3}$.

Quem nunca ouviu esta máxima da cultura pop: "para o alto e avante" e/ ou "lá no alto, vejam, é um pássaro? É um avião? Não é o Super-Homem" ou ainda, "mais rápido que uma bala, mais forte que uma locomotiva, capaz de saltar sobre prédios com um único pulo. Ele é o Super-Homem". Super-Homem é o personagem mais popular da cultura pop. Foi o primeiro super-herói da história das HQ's', criado em 1938, por Jerry Siegel e Joe Shuster. Com o seu surgimento, houve uma mudança drástica, que alterou o panorama das HQ's do planeta, e a própria fisionomia dos quadrinhos para sempre (BRAGA \& PATATI, 2006; p. 67).

Sua primeira aparição foi apresentada na revista Action Comics \#1 em 1938, nos Estados Unidos. Super-Homem foi um sucesso de vendas, e logo ganhou uma revista própria. O sucesso foi tão grande que logo começaram a surgir outros personagens, criando assim um novo gênero das HQ's, as superaventuras. Além disso, Super-Homem é uma figura com potencial mercadológico, sendo licenciadas e adaptadas para diversas mídias, programas de rádio, diversas adaptações para séries animadas e séries para TV (a última foi a série Smallville, que contava histórias da juventude do futuro Super-Homem), sem falar em diversas adaptações para o cinema.

\section{A importância do personagem}

Os jovens judeus, Siegel e Shuster, nunca imaginariam que sua criação chegasse tão longe, com tamanho sucesso. Super-Homem é um símbolo norte-americano desde seu surgimento, sendo que em abril do ano passado (2011), na Action Comics \#900, o personagem Super-Homem fez estremecer o congresso e a sociedade norte-americana; na história de David S. Goyer,

\footnotetext{
${ }^{3}$ Tradução para o português de Superman.

${ }^{4}$ Histórias em Quadrinhos.
} 
o personagem renuncia sua cidadania estaduniense. "Eu pretendo falar ante as Nações Unidas amanhã e informá-los de que estou renunciando à minha cidadania americana". "Verdade, a justiça e o modo de vida americano não são mais suficientes" (CORNNER, WOODS \& MERINO, 2011). A idéia da DC Comics (dona dos direitos do personagem) é tornar o "homem de aço" mais universal. Mas isso causou muita polêmica, e só este pequeno evento já mostra a importância deste personagem. Super-Homem é conhecido como o 'escoteiro azul', pois sua lealdade ao planeta que o adotou é inquestionável. Ele "reconhece a autoridade do Estado, e este, por sua vez, o autoriza a agir em seu nome" (IRWIN, 2008; p. 62). Procura sempre o que é o correto em escala global. É tão venerado que sua história chegou a ser comparada com a vida de Jesus, "lembrando que Super-Homem era um homem enviado do céu por seu pai para usar seus poderes especiais pelo bem da humanidade" (KNOWLES, 2008; p. 142).

Super-Homem evoca a filosofia do filósofo alemão Friedrich Wilhelm Nietzsche (1844-1900) e sua teoria sobre Übermensch, um Homo Superior, que seria um novo animal político, destituído da moral comum. Um homem que inventasse a si mesmo ao invés de aceitar um modelo pré-estabelecido. O Super-Homem de Nietzsche consiste na superação e não na verdade estabelecida; na invenção de si. Mas o Super-Homem dos quadrinhos é um modelo de virtude do filósofo grego Aristóteles, bem diferente da idéia do übermensch nietzscheano.

\section{Um super-herói que encontrou Aristóteles}

Em torno do super-herói Super-Homem surgem freqüentes indagações, como as de Irwin (2005), por exemplo: por que ele faz o que faz? Que motivos o impulsionam para a ação? O que o levou a assumir o papel de protetor e defensor de todos? Por que ele procura sempre fazer a coisa certa? (ibid., p. 17). Clark Kent poderia ter uma vida tranqüila na fazenda de sua família e utilizar proveitosamente sua grandiosa força, por exemplo, espremendo um carvão até que ele virasse diamante, e assim acabar com os problemas financeiros da fazenda. Ele tem poder para ter o que bem pensar, mas passa a maioria do seu tempo protegendo os habitantes deste planeta (ibid.; p. 18). Por que um indivíduo especial, como Clark Kent, gasta a vida para salvar vidas, em vez de usar seus poderes em benefício próprio? Embora não passe de ficção, a história inspira boas questões para nossas reflexões sobre o cotidiano.

Kal-El se disfarça de humano para passar desapercebido, principalmente porque não pode prever qual poderia ser a reação das pessoas ao saberem que ele é um extraterrestre e que tem poder para derreter um carro, 
só com um olhar de raiva (IRWIN, 2005; p. 18). Com certeza a população ficaria amedrontada com este tipo de ser. Por isso Kal-EL se esconde atrás de seus óculos, na identidade de Clark Kent, como cidadão comum. E para ficar perto das pessoas que necessitam de sua ajuda, torna-se um repórter do jornal Planeta Diário. E em hipótese alguma o Super-Homem faz uso de seus poderes em benefício próprio. Na série de TV Smallville ${ }^{5}$, Clark até pensa em não usar seus super-poderes, deixá-los de lado, para satisfazer seu desejo de ter uma vida amorosa com a Lois Lane. Mas isso é impossível para ele porque não se esquece do seu dever moral de proteger a humanidade. O seu caráter é comprometido com a verdade e justiça (ibid., p. 161). Na HQ Super-Homem - Paz na Terra, o homem de aço luta pela vida digna como condição para a paz.

Quando se aproxima o Natal em Metrópolis, o Super-Homem começa a ponderar com um certo desconforto sobre o cruel abismo que separa os poucos privilegiados dos muitos destituídos que beiram a inanição. Decidido a ajudar fazendo de si mesmo um exemplo, o homem de aço resolve empregar todos os seus incríveis poderes num esforço titânico para aliviar a fome no mundo. Apesar do cinismo e das dificuldades que encontra nesta tarefa, seu maior presente para o planeta é uma inegável mensagem de paz e esperança (DINI \& ROSS, 1999; p. 1).

Super-Homem jurou lutar pela liberdade e justiça para proteger o mundo que o acolheu e o aceitou, e assim servir de exemplo de inspiração para as mudanças necessárias para esse fim. No entanto, ele não se sente no direito de interferir diretamente nas ações humanas: "não cabe a mim ditar a política para a humanidade. Mas, se eu combater a fome em escala global, talvez eu inspire outros a fazer o mesmo" (ibid.; p.21). Trata-se da inspiração aristotélica de, mediante ações virtuosas, servir de exemplo para que os que o admiram também se animem em praticar ações virtuosas (Conforme Aristóteles, 2007, X, $1179 \mathrm{~b} ; 35)$.

Na história em quadrinho Super-Homem - Paz na Terra, o Super-Homem é apresentado para identificar a missão que lhe é própria: servir de fonte de inspiração para a própria humanidade. Ele dá o exemplo e espera que outros se juntem a ele. Uma única pessoa não pode resolver tudo, ainda mais quando

\footnotetext{
Smallville é uma série de televisão americana de ficção científica que estreou em 2001 no canal The WB. Criada por Alfred Gough e Miles Millar. A série é baseada na história do mais conhecido superherói da DC Comics de todos os tempos, o popular personagem Super-Homem. A série mostra a vida do adolescente Clark Kent, que vive e cresce em Smallville. Ver Smallville. Direção: Alfred Gouch e Milles Millar. Warner Bros Television, 2001. 6 DVDs, $1^{\text {a }}$ Temporada.
} 
se trata de assunto tão delicado, como a fome. Seja ela um super-herói com capa vermelha, seja o presidente de seu país, o prefeito de sua cidade ou o síndico de seu prédio. Ninguém pode ficar sentado esperando que os outros resolvam as coisas por você. É necessário o engajamento de todos para resolver uma causa tão ampla e difícil (NATALIATO, 1999).

O super-herói kriptoniano, que se domiciliou no planeta Terra e aí recebeu afeto e educação, prima por fazer o "bem". O Super-Homem faz o bem de forma excelente, isto é, da melhor forma possível: ele sente corretamente, pensa de modo certo, decide pelo que é bom e age corretamente (KRAUT, 2009). Eis os critérios da ação virtuosa, segundo Aristóteles. Ele age em conformidade com a virtude que lhe é própria e por isso ele é tão admirado e adotado como exemplo de virtude.

Na perspectiva aristotélica essa excelência moral nada mais é do que uma disposição da alma relacionada com a escolha de ações e emoções, que consistem no meio termo ou na mediania, que caracteriza os seres humanos dotados de discernimento. (ARISTÓTELES, 2007, 1106 b; 17-20). Deste modo, ao agir em conformidade com seu sentimento e a sua razão, fazendo o "bem", o Super-Homem realiza um ato virtuoso (DAL MASS, 2007; p. 25). Segundo o filósofo de $E_{\text {stagira }}$, as ações são virtuosas não somente por serem realizadas em conformidade com a virtude, mas também porque no agente se cumprem certas condições e disposições de espírito.

Citando o próprio Aristóteles, para que tenhamos uma ação virtuosa é necessário que o sujeito tenha conhecimento daquilo que vai fazer, em segundo lugar, tem que eleger deliberadamente o ato e eleger o ato pelo próprio ato; e em terceiro lugar, o ato tem que brotar de uma disposição de caráter estável e permanente (ARISTÓTELES, op. cit., 1105 b; 3-5). E desse modo teremos uma ação realmente virtuosa.

Isso significa que, segundo Aristóteles, o ser humano só é moralmente virtuoso e justo quando pratica um ato bom visando este fim, isto é, "caso ele realize um ato sem tal consciência, mesmo que este venha a ter como resultado algo bom ou justo, não significa que o homem deva ser considerado bom ou justo" (DAL MASS op. cit.; p. 34). Somente o homem que busca o caminho correto, de verdade e justiça, e seu dever moral com a sociedade, é virtuoso, e mais, o ser humano nasce para a cidadania e vive para sociedade na qual está inserido (ARISTÓTELES, op. cit., I, 1097 b; 8-13). Super-Homem segue a seu modo o modelo aristotélico de ser, um homem virtuoso, que deixa suas vontades particulares de lado em benefício do bem comum. De certa forma ele cumpre a prescrição do filósofo quando afirma que a função do ser humano é agir corretamente, é fazer o bem em conformidade com a virtude ou excelência própria à atividade.

\footnotetext{
${ }^{6}$ Uma antiga cidade da Macedônia, situada hoje na Grécia, onde nasceu o filósofo Aristóteles.
} 
Quando o super-herói usa seus dons para fazer o bem à sociedade, ele está agindo como um verdadeiro cidadão planetário, membro da espécie humana, embora ele seja um kriptoniano (LAWRENCE, 2009; p. 54).

\section{Super-Homem e a busca da felicidade aristotélica}

O Super-Homem sabe que ele não é daqui, e não pertence a este mundo. Foi criado entre os humanos; mas, na verdade, não é um de nós, é o último sobrevivente de seu planeta. Ele é um extraterrestre, e se sente só neste planeta, segurando o seu grandioso segredo como um fardo. Ele sente que o desejo básico de pertencer, de fazer parte, que é um dos aspectos fundamentais da natureza humana, está longe de se realizar em sua vida. Segundo Irwin (2005; p. 19), a necessidade de se ligar aos outros, de conviver, parece vital para o bem-estar humano. Mesmo sendo um extraterrestre, Super-Homem sente a mesma necessidade básica de convívio e comunicação. Embora esteja entre os humanos, Super-Homem não dá as costas à sua herança alienígena, só quando usa seus dons naturais kriptonianos é que se sente vivo e engajado. Somente quando deixa de estar escondido por trás de um par de óculos, sendo abertamente kriptoniano, vive em seu potencial, tornando-se um membro da sociedade, um homem do planeta Terra (ibid.; p. 20).

Mas o Super-Homem pode ainda ser tomado como exemplo daquilo que Aristóteles denomina de excelência, ou seja, o caminho para a finalidade da vida humana: a "felicidade". A felicidade é entendida aqui como finalidade última ou como bem supremo e auto-suficiente, expressão que Aristóteles emprega para o convívio do ser humano com os pais, os filhos e à esposa, bem como os amigos e concidadãos em geral, que se relacionam com ele, posto que o ser humano é, por natureza, um ser social (ARISTÓTELES, 2007, 1097 b; 9-11).

Sem exagero, o Super-Homem é esta referência de auto-suficiência para as pessoas à sua volta e para aqueles que necessitam de seu auxílio. É aquela pessoa que por si só, torna a vida desejável e carente de nada. Segundo Pilcher (2004), a felicidade aristotélica é o bem supremo do homem, o mais alto de todos os bens alcançados graças ao hábito de praticar ações virtuosas, é o mais divino de todos os bens humanos.

De todo modo, mesmo que a felicidade não seja a nós enviado do céu, mas sim conquistada pela virtude e por alguma espécie de estudo ou prática, parece ser uma das mais divinas coisas existentes, pois aquilo que constitui a recompensa e a finalidade da virtude se afigura como sendo a coisa mais excelente, além de algo divino e abençoado (ARISTÓTELES, op. cit., 1099 b; 14-16). 
São as ações do homem que o leva para a felicidade, assim como as ações do Super-Homem; ele auxilia aqueles que necessitam de seu socorro, pois sente a necessidade de cumprir esta atividade, usando suas potencialidades kriptonianas, um dever moral. Este super-herói das HQ's, é um grande exemplo de virtuosismo, suas inclinações o impulsionam para o dever de defender as pessoas deste planeta que o acolheu. Essa é a sua forma de realizar ações moralmente virtuosas. Para Irwin (2005), há uma quantidade saudável de interesse próprio nestes atos; ao ajudar os outros, o Super-Homem ajuda a si mesmo, pois cumpre seu destino e sua natureza. Mas em última instância o super-herói é o indivíduo autêntico, que aceita quem ele é, e celebra esse verdadeiro eu usando todos os seus poderes para o bem dos outros e de si mesmo (ibid.; p. 21). Isso faria dele uma pessoa feliz, segundo Aristóteles, o homem virtuoso, age e reflete sobre as ações, de acordo com a virtude e suporta sua sorte do mais belo modo possível e de um modo harmonioso em todos os aspectos (ARISTÓTELES, 2007, 1100 b; 19-20), atualizando todas as suas potencialidades, como o super-herói aqui estudado.

A boa ação constitui o bem supremo humano e, segundo Reeve (2009), "é o primeiro princípio da sabedoria prática, o objetivo, fim ou alvo ao qual a deliberação absolutamente boa visa" (ibid.; p. 191). Ao realizar boas ações ou atos virtuosos o ser humano sente um intenso prazer, segundo Aristóteles (2007, 1099 a; 10), e o Super-Homem certamente tem prazer em usar suas potencialidades em prol dos que necessitam de sua ajuda, auxiliando-lhes. De certa forma, está ajudando a si mesmo, pelo bem-estar que sente em fazer o bem aos outros, embora, é claro, ele deseje o bem dos outros.

Pelos critérios de Aristóteles, ele seria um ótimo exemplo para ilustrar o caráter moralmente virtuoso, porque ao deparar-se com uma situação de injustiça, ele tem sentimento de justiça. Como já foi dito acima, ele pensa corretamente a situação, decide-se para a ação correta e age corretamente. Nele não há espaço para uma contradição entre a inclinação natural e o que é moralmente correto. Além do mais, ele sabe que aquilo que está fazendo é uma ação virtuosa, ele decide livremente por fazê-la e age movido por um caráter irretocável. Em outros termos, ele age de acordo com a justa razão (ibid., 1105 a; 30). O "bem", segundo Aristóteles, é alcançável para todos (ibid., 1096 b; 30), e nas HQ’s do Super-Homem, isso é vivenciado a todo momento.

O bem humano é o exercício ativo das faculdades da alma humana em conformidade com a virtude, ou se houver diversas virtudes, em conformidade com a melhor e mais perfeita delas. Ademais, essa atividade deve ocupar uma existência completa, pois uma andorinha não faz verão, nem produz um belo dia; 


\title{
HUMANAN
}

\author{
e, analogamente, um dia ou um efêmero período de \\ felicidade não torna alguém excelsamente abençoa- \\ do e feliz (ARISTÓTELES, 2007, 1098 a; 15-19).
}

O super-herói busca realizar o bem a todo momento em benefício dos habitantes deste planeta, realizando o dever de proteger a humanidade e de mostrar um caminho correto a seguir, para ser um exemplo para a sociedade. Assim como na HQ Super-Homem - Paz na Terra, este super-herói sabe que sozinho não alcançará seu objetivo (o Bem). Ele precisa do auxílio de todos para poder cumprir a sua missão.

Super-Homem não se esconde atrás de um par de óculos e na atividade de jornalista como Clark Kent. Ele vive como a pessoa que realmente é, um ser com grandiosos superpoderes que aplica a serviço dos outros, assumindo assim, seu lugar justo na comunidade, da qual agora ele faz parte e na qual se sente realizado (IRWIN, 2005; p. 20), com exuberância e excelência. Assim Aristóteles afirma:

\begin{abstract}
Achar-se-á, então, no homem feliz aquele que se procura, e ele será tal durante a vida: pois sempre ou então com preferência a qualquer outra coisa, encaminhará a obra e a mente às ações virtuosas e suportará galhardamente os azares da fortuna, em tudo e por tudo como convém: daquele, precisamente, que é verdadeiramente bom (ARISTÓTELES, 2003; p. 42).
\end{abstract}

Super-Homem quando vive em total autenticidade, aceitando com naturalidade seus dons e aplicando estes a serviço dos outros, ele vive em excelência. Ao mesmo modo, Aristóteles, em sua obra Ética a Nicômaco, que estudava a felicidade como a finalidade do homem, começou a observar o que é viver em excelência, enunciando assim: "se a felicidade consiste na atividade de acordo com a virtude, é razoável que seja atividade de acordo com a virtude maior (excelência), e esta será a virtude da melhor parte de nós" (ARISTÓTELES, 2007. X, 1177 a1.; 10-14). De certo modo, Super-Homem, o personagem mais conhecido das histórias em quadrinhos de superaventuras, vivencia em suas aventuras, a finalidade do homem para Aristóteles, a felicidade.

\section{Considerações finais}

Os Super-Heróis além de ser um ícone popular de entretenimento, trazem assuntos vividos no dia-a-dia de cada ser humano. A busca por questões éticas, 
está sendo retratada como pano de fundo em todas as HQ's do Universo Comics ${ }^{7}$, justiça e ordem são o que esse mais vê nestas histórias.

Não é porque Aristóteles tenha dito que o filósofo pode especular sobre todas as coisas que a gente se debruça sobre as histórias em quadrinho de super-herói e suas adaptações para as animações da TV e para o cinema. Elas podem ser objeto de investigação para a filosofia e para muitas ciências, como a sociologia, a psicologia, a teologia, a literatura, dentre outras. Mas o que nos interessa mais de perto é o aspecto pedagógico que Super-Homem das HQ's representam, especialmente na formação do ideal de vida das crianças e dos adolescentes, mais especificamente, na formação da consciência moral.

Se Piaget e Kohlberg têm alguma razão quanto aos estágios de desenvolvimento da consciência moral, as HQ's cumprem uma enorme importância na gênese e na formação da consciência moral. O Super-Herói inspira a internalização da norma como algo bom, e em certa fase até como algo quase que sagrado. A autoridade de um princípio vem daquele que o apresenta. De mais a mais, Super-Homem ensina pelo exemplo, eles mostram pela ação o que é bom e justo. E isso é muito mais eloqüente do que os conselhos em abstrato. E é também aristotélico: aprende-se ao seguir o exemplo das pessoas mais virtuosas, mas a virtude se mostra nas ações do cotidiano.

Então, além da finalidade explícita de proporcionar entretenimento, as histórias em quadrinhos do Super-Homem, apresentam questões relacionadas ao comportamento moral e dá exemplo de virtuosismo para os seres humanos enfrentarem os problemas morais do dia-a-dia. Ele mostra vivencialmente às questões que enfrentamos no cotidiano. Embora sejam produzidas para que o grande público as consuma como diversão, as HQ's podem receber esta forma de leitura mais criteriosa, filosófica, que mostra o aspecto ético que as perpassa.

Se seguirmos a receita do super-herói Super-Homem na HQ Paz na Terra, não combatemos a grande praga do mundo, a fome e desnutrição? A coragem da família Kent em adotar um extraterrestre, e cuidá-lo e protegêlo, como se fosse um filho humano. O exemplo de boa atitude, luta e busca de direitos humanos, estão muito bem retratadas nas HQ's. Para o filosofo grego Aristóteles, necessitamos de bons exemplos para adquirir a virtude. O exemplo que este filósofo grego fala, pode estar nas histórias em quadrinhos de Super-Heróis.

\section{Referências bibliográficas}

ARISTÓTELES. A ética: textos selecionados. $2^{\mathrm{a}}$ edição. Tradução: C.M. Fonseca. Bauru, SP: Edipro, 2003.

${ }^{7}$ História em quadrinhos de Super-Heróis americanos. 
ARISTÓTELES. Ética a Nicômaco. $2^{\text {a }}$ edição. Tradução: E. Bini. Bauru, SP: Edipro, 2007.

BRAGA, F. \& PATATI, C. Almanaque dos quadrinhos. Rio de Janeiro: Ediouro, 2006.

CORNNER, P.; WOODS, P. \& MERINO, J. Action comics. Nova York: DC Comics, Apr. 2011, nº 900.

DALL MASS, A. A lei como fonte de justiça em Aristóteles. Porto alegre, RS: Imprensa Livre, 2007.

DINI, P. \& ROSS, A. Super-Homem - Paz na Terra. São Paulo: Abril/DC Comics, 1999, edição especial.

GOUCH, A. \& MILLAR, M. Smallville. Direção: Alfred Gouch e Milles Millar. Warner Bros Television, 2001. 6 DVDs, $1^{\text {a }}$ Temporada.

IRWIN, W. (Org.). Batman e a filosofia: o cavaleiro das trevas da alma. Tradução: M. Maluezzi. São Paulo: Madras, 2008.

IRWIN, W. (Org.). Super-heróis e a Filosofia: verdade, justiça e o caminho socrático. Tradução: M.M. Leal. São Paulo: Madras, 2005.

KNOWLES, C. Nossos deuses são super-heróis. Tradução: M. Borges. São Paulo: Cultrix, 2008.

KRAUT, R. Aristóteles: a ética a Nicômaco. Porto Alegre: Artmed, 2009.

LAWRENCE, C. Os tratados éticos de Aristóteles. In: R. KRAUT. Aristóteles: a ética a Nicômaco. p. 21-41. Porto Alegre: Artmed, 2009.

NATALIATO, S. Superman - Paz na Terra. 1999. Disponível em <http:// www.universohq.com>. Acesso em 10 de Julho/2011.

PILCHER, N.A. A felicidades na ética de Aristóteles. Passo Fundo, RS: UPF, 2004.

REEVE, C.D.C. Aristóteles e as virtudes do intelecto. In: R. KRAUT. Aristóteles: a ética a Nicômaco. p. 186-203. Porto Alegre: Artmed, 2009.

SIEGEL, J. \& Shuster, J. Superman. Crônicas. Rio de Janeiro: Panini Comics/ DC Comics, 2007, Volume I. Edição Histórica.

THOMAS, R. \& LARK, M. Superman. A guerra dos mundos. São Paulo: Mythos Editora/DC Comics, 2001. 